\title{
Genes on B chromosomes of vertebrates
}

\author{
Alexey I Makunin ${ }^{1,2}$, Polina V Dementyeva ${ }^{1}$, Alexander S Graphodatsky ${ }^{1,3}$, Vitaly TVolobouev ${ }^{4}$, Anna V Kukekova ${ }^{5}$ \\ and Vladimir A Trifonov ${ }^{1,3^{*}}$
}

\begin{abstract}
Background: There is a growing body of evidence that B chromosomes, once regarded as totally heterochromatic and genetically inert, harbor multiple segmental duplications containing clusters of ribosomal RNA genes, processed pseudogenes and protein-coding genes. Application of novel molecular approaches further supports complex composition and possible phenotypic effects of B chromosomes.

Results: Here we review recent findings of gene-carrying genomic segments on B chromosomes from different vertebrate groups. We demonstrate that the genetic content of B chromosomes is highly heterogeneous and some B chromosomes contain multiple large duplications derived from various chromosomes of the standard karyotype. Although B chromosomes seem to be mostly homologous to each other within a species, their genetic content differs between species. There are indications that some genomic regions are more likely to be located on B chromosomes.
\end{abstract}

Conclusions: The discovery of multiple autosomal genes on B chromosomes opens a new discussion about their possible effects ranging from sex determination to fitness and adaptation, their complex interactions with host genome and role in evolution.

Keywords: B chromosomes, Segmental duplication, Proto-oncogenes, Vertebrates, Evolution of genomes

\section{Introduction}

Supernumerary chromosomes were first described by Wilson [1] in the bug of the genus Metapodius. Later dispensible karyotypic elements were also found in rye and maize [2-4] and Randolph [5] suggested the term "B chromosomes" in 1928 to underline the nonessential nature of these elements. Since then B chromosomes (or supernumeraries, extra chromosomes, or Bs) have been found in all major eukaryotic clades. In mammals, where the majority of about 5000 known species are karyotyped, B chromosomes were reported for 75 species ([6], our data).

The variation in number of Bs between populations, individuals or even cells and tissues within an individual might be explained by their mitotic instability and existence of specific accumulation mechanisms acting during process of gametogenesis. Early works on mammalian B chromosomes accumulated data from different species

\footnotetext{
* Correspondence: vlad@mcb.nsc.ru

${ }^{1}$ Institute of Molecular and Cellular Biology SB RAS, Novosibirsk 630090,

Russia

${ }^{3}$ Novosibirsk State University, Novosibirsk, Russia

Full list of author information is available at the end of the article
}

and compared them with data on supernumerary chromosomes of invertebrates and plants, resulting in the idea that B chromosomes represent a system complementary rather than competitive to autosomes [7].

Different theories were proposed regarding B chromosome origin and dispersal within populations. Usually it was hypothesized that B chromosomes originate from autosomes of host species or result from interspecific hybridization (see $[8,9]$ for review). An interesting theory postulates that Bs occur more frequently in genomes with more acrocentric chromosomes due to the centromeric drive in female meiosis [10].

In contrast to other supernumerary karyotype elements (e.g., double minutes [11] or small supernumerary marker chromosomes [12]), B chromosomes are somehow preserved in host species over many generations and spread over many individuals within populations. The reason for their stability may lie in the B chromosome genetic content. In this case, evidence of enrichment with some genomic elements in Bs would shed light on the mechanisms of their prevalence and stability in the populations of some (but not all) species. 
Traditionally, B chromosomes were considered to be totally heterochromatic (i.e. transcriptionally inactive) or, if they had evolved recently, to be undergoing the heterochromatization process according to Muller's ratchet mechanism. Indeed, the heterochromatic nature of $\mathrm{B}$ chromosomes agrees with the fact of their high variability, and these elements often demonstrate typical C-positive staining, although $\mathrm{C}$-negative $\mathrm{B}$ chromosomes also exist in mammals [13-15].

\section{Review}

\section{Molecular structure of B chromosomes}

Early cytogenetic studies of B chromosome molecular composition used available repetitive probes to find specific sequences localized on Bs. These could be tandemly arranged repetitive elements [16], LINEs (long interspersed nuclear elements) and SINEs (short interspersed nuclear elements) [17], interstitial telomeric sequences [18,19], ribosomal DNA clusters [20,21], or histone genes [22]. These studies confirmed the presence of different repetitive elements (also occurring in the standard genome) on Bs in all studied species. Further studies of B chromosomes involving $\mathrm{B}$ chromosome isolation by either flow sorting or microdissection followed by reverse painting failed to provide information about any homologous regions between autosomes and B chromosomes [23-25]. Only localization of BAC (bacterial artificial chromosome) clones and sequencing of isolated B-specific DNA fragments led to the identification of non-repetitive sequences on Bs [25]. The application of these techniques significantly changed our view of the molecular composition of supernumeraries.

With the development of high throughput sequencing technologies, the rapid growth of genomic sequence data provides new insights into chromosomal organization in all branches of the tree of life. In vertebrates, most comprehensive studies have been performed on mammals. Over $95 \%$ of DNA sequence is assembled into chromosomes for human, the remainder being mostly satellite DNA in centromeric and pericentromeric regions. Regularities of genome organization were discovered, such as the abundance of "gene islands" and "gene deserts", the proportion and distribution of various repeat families, and the presence of ultra-conserved elements and long non-coding RNAs in non-coding regions [26-28]. The application of novel methods of high throughput sequencing, coupled with a growing knowledge of genome organization, together open a new chapter in B chromosome studies.

\section{Genes on B chromosomes of canids}

Canids represent an outstanding order of mammals in terms of chromosomal evolution rates [29]. Additionally, a higher number of canid species with B chromosomes has been reported in comparison to other mammalian groups. B chromosomes were observed in genomes of red, Bengal and pale foxes (Vulpes vulpes, $V$. bengalensis and $V$. pallida) [30-32], Japanese and Chinese raccoon dogs (Nyctereutes procyonoides procyonoides and N. $p$. viverrinus) [33,34], the short-eared dog (Atelocynus microtis) [35] and the maned wolf (Chrysocyon brachyurus) [36]. Among B-carrying canids, the most intensive karyotype studies were accomplished in red foxes and raccoon dogs $[29,30,33,34,37]$. In the 1970 s, the B chromosomes of the red fox were thoroughly studied to detect number variation patterns between and within individuals [30], late replication timing [38], and preferential segregation towards reproductive cells [39]. Classical cytogenetic studies revealed clusters of inactive ribosomal genes, interstitial telomeric sequences, and complex chromatin structure in raccoon dog B chromosomes [18,19]. Later, B chromosomes of red foxes and raccoon dogs were isolated by microdissection [25] and flow sorting ([24] and our unpublished data) and the resulting B specific DNA libraries were used in reverse painting FISH experiments.

The first autosomal gene - C-KIT (v-kit HardyZuckerman 4 feline sarcoma viral oncogene homolog) was discovered by chance on red fox B chromosomes during the fox genome mapping project using canine BAC clones. Later the same gene was discovered on B chromosomes of Chinese and Japanese raccoon dogs [40]. Autosomal C-KIT contains 21 exons [41] and encodes a transmembrane tyrosine kinase regulating proliferation and cell differentiation of melanoblasts, blood cells, and primordial germ line cells [42]. The RNA coding region (1100 bp) of the C-KIT gene is homologous to provirus of feline Hardy-Zukerman sarcoma 4 [43]. Mutations in C-KIT can cause gut stromal cancers in human, mouse, dog and rat [44]. Many mutations identified in C-KIT lead to a white spotting pattern of coat color [45]. While this pattern is widely distributed across mammals, its causative mutations vary: these can be missense substitutions [45-47], exon skipping [48], duplication combined with splice mutations [49] or retrovirus insertions [50]. Detection of BAC signals on canid B chromosomes might also be caused by the presence of rather small but highly amplified unique segments. To exclude this possibility, the C-KIT-containing region was analyzed using PCRassisted mapping and sequencing. The autosomal fragment on fox B chromosomes was found to encompass at least $480 \mathrm{kbp}$ and to include the C-KIT gene, the pseudogene RPL23A and a large intergenic spacer on both the 3' and 5 ' gene flanking regions. The fragment of the raccoon $\operatorname{dog} \mathrm{B}$ chromosomes was found to be even larger and to contain at least $490 \mathrm{kbp}$ including C-KIT, the pseudogene $R P L 23 A$, part of the $K D R$ (kinase insert domain receptor) gene and a large intergenic spacer on the 5 ' end of C-KIT [51]. 
Some new data on the C-KIT containing segment came from the fox genome sequencing project. The genomes of six red foxes were sequenced with $6 \mathrm{X}$ coverage each and aligned against the dog genome (CanFam3.1). A significant increase in the number of sequencing reads was observed in a $206 \mathrm{kbp}$ region on dog chromosome 13 (CFA13) containing a partial sequence of the C-KIT gene (chr13: 47,122-47,328 kbp) (Figure 1). The region corresponding to the $C$-KIT promoter, exon one, and part of intron one did not show a read depth increase [48]. The increase in read depth in the region including the partial sequence of $C-K I T$ is likely caused by the presence of this region on fox $B$ chromosomes. The depth of reads in this region varied among individuals, suggesting that sequenced individuals carried different numbers of B chromosomes in their genomes. An additional confirmation of the presence of the C-KIT region on fox $\mathrm{B}$ chromosomes was obtained through sequencing a red fox, flow sorted, B chromosome specific DNA library (Degenerate Oligonucleotide Primed PCR) ([25,52], Makunin et al., in preparation).

These novel sequencing data suggest that the C-KIT copy on B chromosomes of the red fox is not translated or is not fully functional. The results partly disagree with previously published data reporting the presence of a full B chromosomal copy of the gene. B specific library sequencing has revealed that total genomic DNA contamination occurs in virtually all flow sorted samples and there is a need for statistical estimates to make conclusions about the presence or absence of specific DNA segments. Therefore, the data on PCR assisted mapping of chromosome specific libraries should be supplemented by other approaches to ensure the results are correct.

Numerous protein coding sequences on fox B chromosomes were discovered using cDNA selection strategy. Briefly, DOP-PCR amplified libraries obtained from sorted fox B chromosomes were used as probes in SHAC (Selection of Hybrids by Affinity Capture) to enrich total fox cDNA with B-specific transcripts. Sequencing of about 40 randomly selected clones of enriched cDNA libraries resulted in the identification of several new putative regions homologous to autosomes. To confirm the presence of the respective sequences on $\mathrm{B}$ chromsomes, caninecharacterized BACs, containing homologous genes, were localized on fox and raccoon dog B chromosomes using

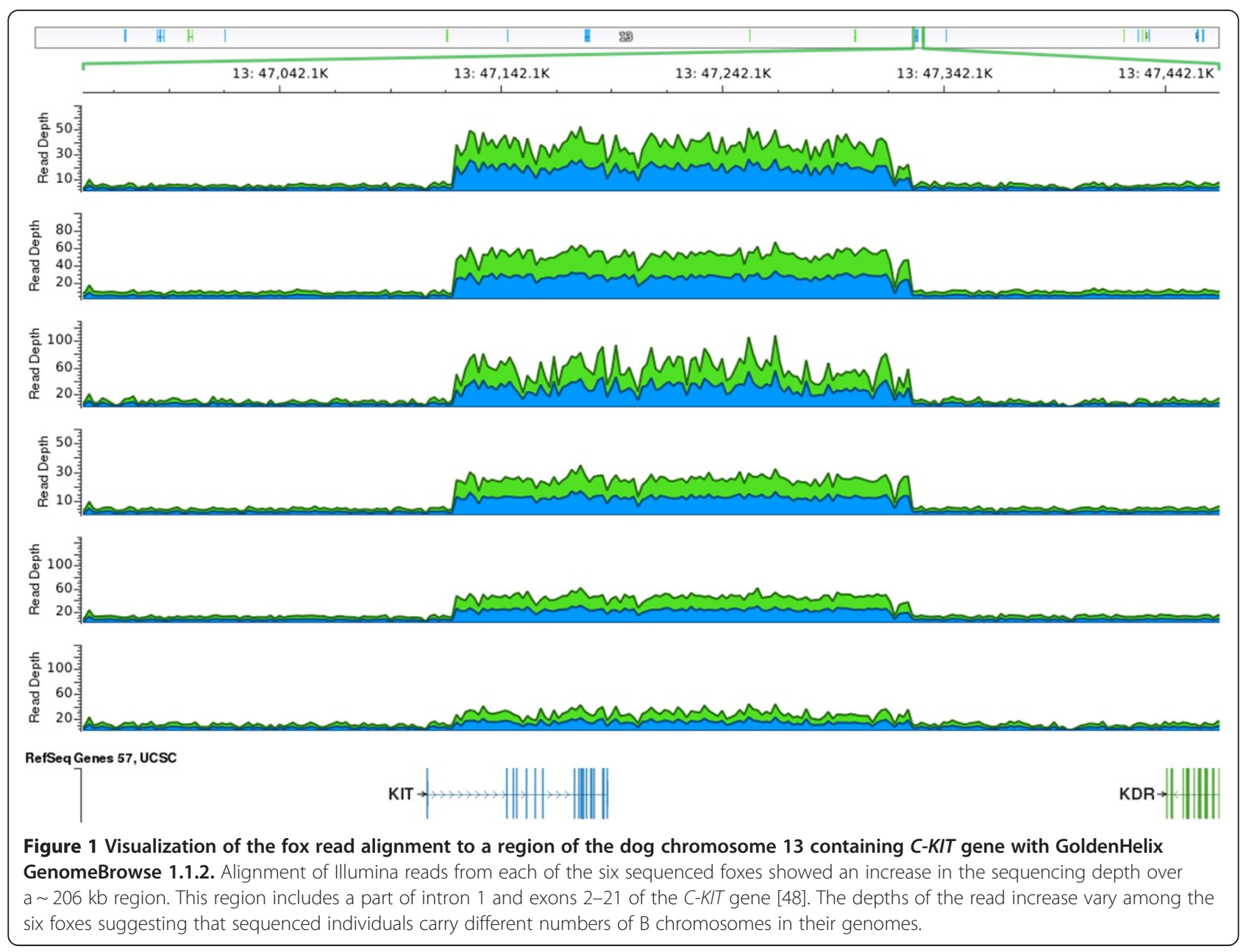


FISH (fluorescent in situ hybridization) [53]. These data confirmed the presence of $C-K I T$ and revealed over a dozen new autosomal protein-coding gene containing regions on canid B chromosomes (Table 1). Segments of 10 autosomes were discovered on B chromosomes of Canidae, seven of which were present on fox Bs, five on Chinese raccoon dog Bs, and only a single one on Japanese raccoon dog Bs. One of the largest regions, associated with the LRIG1 (leucinerich repeats and immunoglobulin-like domain protein 1) gene, showed homology to a $601 \mathrm{kbp}$ interval in the dog and was represented in six overlapping BAC clones. This region was identified only in Chinese raccoon dog B chromosomes. Notably, among ten B chromosomal regions, at least four contained proto-oncogenes: C-KIT, LRIG1, RET (receptor tyrosine kinase), CTNND2 (cadherin-associated protein) or a tumor suppressor gene, $L R P 1 B$ (LDL receptor related protein 1B) [53].

Only the C-KIT-containing region (CFA13) was found to be present on $\mathrm{B}$ chromosomes of all three canid species (Table 1). A second CFA13 region, located $\sim 12.5 \mathrm{Mbp}$ from the $C$-KIT gene in the dog genome, was present on both fox and Chinese raccoon $\operatorname{dog} B$ chromosomes. All other regions were found to be species-specific.

Although FISH analysis revealed the presence of multiple genomic regions on B chromosomes, the exact copy number of duplicated segments remained unclear. In our previous study we obtained region-specific libraries from $\mathrm{B}$ chromosomes of the Japanese raccoon dog by microdissection [25]. Using these probes in FISH experiments we showed a significant homology and similarity in DNA content between the $\mathrm{B}$ chromosomes of Chinese and Japanese raccoon dogs (our unpublished data, Figure 2). However, many autosomal segments identified in Chinese raccoon dog Bs by BAC mapping were not found in Japanese raccoon dog Bs [53], which may indicate that the FISH results mostly demonstrated repetitive sequence content. Thus, additional experiments are needed to identify the missing content of the rather large Japanese raccoon dog B chromosomes.

Taken together, these findings confirmed the hypothesis of the autosomal origin of B chromosomes in canids and raised questions about the mechanisms preserving the striking conservation of B-chromosomal sequences, since the common content of canid Bs might presume their common origin and 16 million years of independent evolution [40,54]. An alternative explanation for this phenomenon is based on the possibility that some sequences are re-used for $\mathrm{B}$ chromosome formation in various lineages independently. For example, we recently discovered the presence of the C-KIT gene on Bs of the cervid species brown brocket deer (Mazama gouazoubira) (Makunin et al., in preparation).

Table 1 The list of the genes localized on vertebrate B chromosomes

\begin{tabular}{|c|c|c|c|}
\hline Gene & Species & Function (from GO) & References \\
\hline \multirow{3}{*}{$\begin{array}{l}\text { C-KIT (v-kit Hardy-Zuckerman } 4 \text { feline } \\
\text { sarcoma viral oncogene homolog) }\end{array}$} & Vulpes vulpes & \multirow{3}{*}{$\begin{array}{l}\text { Protooncogene, encoding a type } 3 \\
\text { transmembrane receptor }\end{array}$} & \multirow[t]{3}{*}[40,51,53]{} \\
\hline & Nyctereutes procynoides procynoides & & \\
\hline & N.p. viverrinus & & \\
\hline \multirow[t]{2}{*}{$K D R$ (kinase insert domain receptor) } & N.p. procyonoides & \multirow{2}{*}{$\begin{array}{l}\text { Protooncogene, encoding a tyrosine } \\
\text { kinase receptor }\end{array}$} & \multirow[t]{2}{*}[51]{} \\
\hline & N. p. viverinus & & \\
\hline RET (ret proto-oncogene) & N.p. procyonoides & $\begin{array}{l}\text { Protooncogene, encoding a tyrosine } \\
\text { kinase receptor }\end{array}$ & {$[53]$} \\
\hline $\begin{array}{l}\text { LRIG1 (leucine-rich repeats and } \\
\text { immunoglobulin-like domains 1) }\end{array}$ & N. p. procyonoides & Tumor suppressor gene & [53] \\
\hline $\begin{array}{l}\angle R P 1 B \text { (low density lipoprotein } \\
\text { receptor-related protein 1B) }\end{array}$ & V. vulpes & $\begin{array}{l}\text { Tumor suppressor gene, encoding a } \\
\text { low density lipoprotein (LDL) receptor }\end{array}$ & {$[53]$} \\
\hline CTNND2 (cadherin-associated protein) & V. vulpes & $\begin{array}{l}\text { Protooncogene, encoding a adhesive } \\
\text { junction associated protein }\end{array}$ & {$[53]$} \\
\hline IHHB (Indian hedgehog homolog b) & Lithocromis rubripinnis & Embryonic morphogenesis regulation & {$[59]$} \\
\hline Lysosomal alpha-mannosidase & L. rubripinnis & Exoglycosidase & {$[59]$} \\
\hline Rnasel 2 (Ribonuclease-like 2) & L. rubripinnis & Ribonuclease & {$[59]$} \\
\hline VPS10 domain receptor protein SORCS 3-like & L. rubripinnis & Neuropeptide receptor & [59] \\
\hline Ryanodine receptor-like unnamed protein & L. rubripinnis & Calcium channels & {$[59]$} \\
\hline TNNI3K (TNNI3 Interacting Kinase) & Capreolus pygargus & Protein serine/threonine kinase activity & {$[55]$} \\
\hline FPGT (Fucose-1-phosphate guanylyltransferase) & C. pygargus & Guanylyltransferase & {$[55]$} \\
\hline $\begin{array}{l}\text { LRRIQ3 (Leucine-Rich Repeats And IQ } \\
\text { Motif Containing 3) }\end{array}$ & C. pygargus & Not clear & {$[55]$} \\
\hline
\end{tabular}



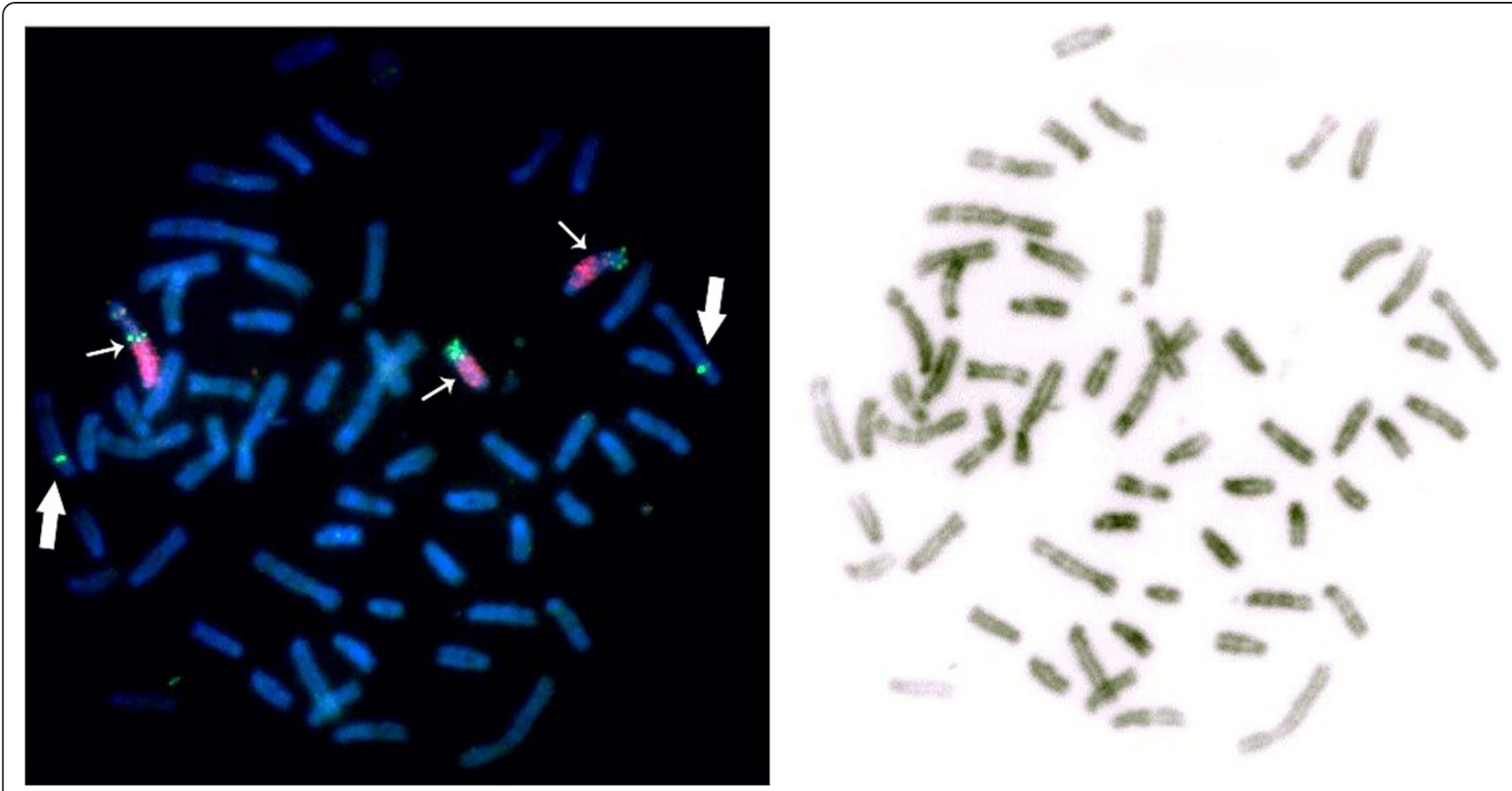

Figure 2 The localization of the CKIT containing canine BAC 265 L-22 (green) and a probe specific for the proximal region of Japanese raccoon dog $\mathbf{B}$ chromosomes (red) on Chinese raccoon dog B chromosomes. Small arrows indicate B chromosomes; large arrows indicate chromosome 6, where the original copy of CKIT is located.

\section{B chromosomes of the Siberian roe deer}

In the Cervidae family, B chromosomes were identified in the genomes of two genera: Mazama and Capreolus. A recent study of B chromosome content and activity in the Siberian roe deer (Capreolus pygargus) was the first to indicate that some genes on B chromosomes are transcribed in vertebrates [55]. A candidate $2 \mathrm{Mbp}$ region including FPGT, LRRIQ3 and TNNI3K genes was found on B chromosomes of Siberian roe deer by a B-specific cDNA selection approach (see Table 1 for gene details). The presence of these three genes on B chromosomes of this species was further confirmed using FISH with bovine BAC clones, PCR-assisted mapping, real-time PCR and Bspecific library sequencing. Interestingly, these genes were shown to be unevenly amplified among Bs of Siberian roe deer. Sequencing of B-specific and autosomal copies of the three genes revealed mutations specific for B chromosomes. One of these B-specific mutations was found in a transcript of the FGPT gene, thus demonstrating transcription of a B-specific gene copy. These novel data generally challenge the view of totally silent $B$ chromosomes in vertebrates, and promise similar new discoveries in other species.

\section{B chromosomes of cichlid fishes}

In cichlid fishes, B chromosomes have been identified in seven South American and fourteen African species [56-60]. Cichlids represent a model for adaptive radiation and extensive genomic resources are available for several representatives of the group: genetic and physical maps for several species and sequenced genomes of four species (Astatotilapia burtoni, Pundamilia nyererei, Metriaclima zebra and Neolamprologus brichardi). Recent studies in two cichlid species provide new insights on the genetic content, origin, and functions of B chromosomes.

\section{Genes on B chromosomes of Lithocromis rubripinnis, a cichlid species of Lake Victoria}

In one of populations of Lithocromis rubripinnis, a cichlid species from Lake Victoria [59], only females carried B chromosomes. Experimental breeding of B-lacking individuals produced progeny with a sex ratio close to 1:1, while but B-carrying animals had a much higher proportion of female offspring (up to 100\%). The authors suggested that in this case sex determination was directly linked to B chromosomes.

A library of BAC clones from a B-carrying L. rubripinnis individual was created and B-chromosome-specific clones were identified based on differential hybridization with genomic DNA of individuals with $(\mathrm{B}+)$ and without (B-) B chromosomes. The analysis of $\mathrm{B}$ chromosome specific DNA from BAC clones revealed a B-specific repeat and fragments of five protein-coding genes. These genes were proposed to be functional as no nonsense mutations were found, but none of these genes was thought to be directly involved in sexual development (Table 1). One of the 
genes, IHHB (indian hedgehog homolog b), was extensively amplified - about 40 copies were found in the $L$. rubripinnis genome by qPCR.

Using FISH for BAC-clone localization, the authors showed that Bs were homologous to the short arm of chromosome 1 . This region arguably contains loci responsible for sex determination. Although the origin of some B chromosomes from sex chromosomes was proposed earlier (reviewed in [8]), the extraordinary feature of the role of B chromosomes in sex determination was demonstrated here for the first time.

\section{DNA content of B chromosomes in the cichlid astatotilapia latifasciata}

Another recent study investigated the genetic content of $\mathrm{B}$ chromosomes in Astatotilapia latifasciata, a cichlid species from lake Nawampasa (Lake Kyoga system, Africa), using a whole genome sequencing approach [61]. Briefly, Illumina HiSeq reads (23X coverage for an individual carrying $\mathrm{B}$ chromosomes $(\mathrm{B}+)$ and $31 \mathrm{X}$ coverage for an individual without $\mathrm{B}$ chromosome (B-)) were mapped to the Metriaclima zebra reference genome. Genomic regions specific to B chromosomes (B-blocks) were identified based on difference coverage of normalized $\mathrm{B}+$ and B- libraries. To test these results, DNA from a microdissected B chromosome was amplified and sequenced using the Roche 454 platform. Reads were assembled in contigs and mapped to the same M. zebra reference genome after filtering out human contaminants.

The resulting positions of B-specific sequences were in good agreement between the two methods. B-blocks were distributed among most linkage groups of $M$. zebra, but the largest blocks were identified in linkage groups 1 , 3 and 9 (165, 177 and $146 \mathrm{kbp}$, respectively). Interestingly, these blocks include genes previously identified on B chromosomes in cichlids from Lake Victoria (Lithochromis rubripinnis) $[59,60]$. Based on this fact, the authors proposed a common origin of B chromosomes in these species. The study of gene content of B-blocks has shown that only $3.2 \%$ of 5,858 putative $\mathrm{B}$ genes (including processed pseudogenes) had over $50 \%$ of their sequence present on B chromosomes. FISH mapping and qPCR confirmed B-specific localization and copy number changes of the HPRT gene. Among genes with high integrity, the authors highlighted several genes involved in chromosomal segregation: proteins involved in microtubule organization (TUBB1, TUBB5), kinetochore structure (SKA1, KIF11, CENP-E), recombination (XRCC2, SYCP2, RTEL1) and progression through the cell cycle (Separase, AURK). Trancriptome analysis revealed that B-chromosomal copies of the Separase, TUBB1 and KDF11 genes are expressed, but evolve under neutral selection.

Authors proposed a scenario of B chromosome origin: segmental duplications including the centromeric region with subsequent formation of an isochromosome, amplification of sequences and introgression of additional segments from the main genome through transposable and retrotransposable elements and ectopic recombination.

\section{Genes on B chromosomes of the Amazon molly Poecilia formosa (Poecillidae, Cyprinodontiforme)}

In the Amazon molly Poecilia formosa (Poecillidae, Cyprinodontiforme), expression of genes affecting pigmentation was shown to be linked with the occurrence of B chromosomes in the karyotype [62]. Moreover, additional chromosomes of this species harbor an uncharacterized locus that confers a higher susceptibility to pigment cell tumors [63]. In a recent study the presence of a unique region on $\mathrm{B}$ chromosomes of this species was shown using AFLP (amplified fragment length polymorphism). The Southern hybridization confirmed that this region is represented by a single copy and is conserved within the Poecilia genus [64].

\section{Insights from studies of B chromosomes in non-vertebrate organisms}

The overall picture of nature of supernumeraries would be incomplete without mentioning numerous studies of $B$ chromosomes in taxa beyond vertebrates. Because of the scope of our review we will only briefly summarize the results of some outstanding B chromosome studies in three groups: fungi, flowering plants, and orthopterans.

The presence of genes on supernumerary chromosomes was first predicted in antibiotic resistance studies of the fungus Nectria haematococca $[65,66]$. Later studies further characterized a gene located on additional karyotypic elements of $N$. haematococca and provided evidence of its expression [67]. A recent $N$. haematococca genome sequencing project revealed that supernumeraries are enriched in genes which potentially expand the ecological niche of the host.This study also revealed B chromosome specific genes similar to those from different fungi species, and even some regions supposedly originating from horizontal gene transfer [68].

A number of $\mathrm{B}$ chromosome studies have been performed in plants. B chromosomes are present in hundreds of flowering plant species, including economically important ones such as rye, oat and maize $[9,69]$. A map of high-copy repetitive sequences in $\mathrm{B}$ chromosome was constructed in rye [70], and regions connected with meiotic non-disjunction [71] and expressed pseudogenes [72] were identified. High-throughput sequencing of flowsorted B chromosomes was performed in rye [73] and maize (Blavet et al., unpublished data) in both cases revealing that $\mathrm{B}$ chromosomes include extended genomic regions with some genes present. The presence of transcriptionally active genes on some oat (Avena saliva L.) 
B chromosomes was shown by their effects on host resistance to rust [74].

Another group with actively studied B chromosomes is the Orthoptera family in insects. While many studies are devoted to B chromosome evolution and population dynamics, some interesting results concerning $\mathrm{B}$ chromosome molecular composition were obtained. In the migratory locust, copies of ribosomal genes were found to be active on B chomosomes [75]; divergence between $\mathrm{H} 3$ and $\mathrm{H} 4$ histone gene copies located on B chromosomes and chromosome 8 was used to estimate the age of supernumeraries in this species [22].

\section{Possible effects of B chromosomes on fitness}

The application of current methods of molecular biology such as FISH, sequencing, real-time PCR, and AFLP allowed the localization of specific sequences, including protein-coding genes (listed in Table 1), on B chromosomes of several vertebrate species. These sequences seem to be amplified on B chromosomes $[53,59,61]$. The presence of genes involved in various processes like oncogenesis [53,64], sex determination [59] and cell division [61] on vertebrate B chromosomes indicates that supernumeraries may play a particular role in the development and overall fitness of host organisms. High throughput sequencing technologies provide an intriguing possibility for obtaining an overall picture of B chromosome sequence, expression and epigenetic status [61,73]. Investigation of $\mathrm{B}$ chromosomes using these methods will lead to insights into chromosome structure, function and evolution, and may also provide an impetus for constructing chromosome-based vectors, namely mammalian artificial chromosomes (MACs).

\section{Role of B chromosomes in the evolution of genomes} Little is yet known about the role of B chromosomes in the evolution of genomes. How do they originate? Why do they occur more frequently in some species than in others? Are they short term events or do they persist in genomes for a long time? Further analysis of the molecular content of the B chromosomes can answer some of these questions.

The mapping of $\mathrm{B}$ chromosomes in the vertebrate species considered above $[40,53,55,59,61,64]$ revealed the presence of large autosomal regions containing proteincoding genes. Regions mapped on B chromosomes show a significant similarity with homologous autosomal regions $([59,64]$ and our unpublished data). Therefore we can conclude that most B chromosomes contain segment duplications [76].

Segment duplications originate as a result of improper recombination. In most cases they are tandemly arranged and can be subsequently transposed to distant genomic regions. It has been shown that even partially duplicated genes can be functional [77], indicating that incomplete gene copies on $\mathrm{B}$ chromosomes may also play some role in cell metabolism. Moreover, B-chromosomal and autosomal copies of genes are highly homologous, which can be treated as indirect evidence of their functionality $[55,59,64]$. Amplified copies of genes located on B chromosomes, if they are expressed, can affect the host organism. For example, changes in the copy number of functional C-KIT genes may lead to changes in pigmentation, gametogenesis disorders or various cancers [78-80]. Duplicated genes on B chromosomes can accumulate mutations, theoretically resulting in new functions or domain fusion of previously unassociated genes, similar to the effects of segment duplications described above.

A significant number of genes amplified on B chromosomes are connected with oncogenesis $[40,53,64]$. In mammals, oncogene amplification leads to the formation of homogeneous staining regions (HSRs) and double minute (DM) chromosomes [11]. HSRs represent amplified chromosome regions containing oncogenes, and DMs are small circular autonomic acentromeric chromosomes with the same content. The similarity between Bs and HSRs/DMs is not limited to their genetic content. B chromosomes may also lack typical centromeric DNA (alphoid satellites) (unpublished data by DV Yudkin) and behave irregularly during cell divisions. Similar properties are characteristic for DMs [81].

HSRs and DMs have been intensively studied. Among other results, various mechanisms have been proposed for their formation: the breakage-fusion-bridge model postulates amplification of genes near chromosomal breakpoints; the translocation-deletion-amplification model posits that HSRs and DMs are formed from breakpoint regions in translocation events; and the deletion-plus-episome model assumes excision of a DNA segment with further circularization, amplification and mutual recombination [82]. Based on the many similarities between Bs and HSRs/ DMs, we can propose that some of the mechanisms involved in B chromosome formation may be common with those described for HSRs and DMs.

Recent findings in cattle indicate that color sidedness [83] and gonadal dysgenesis [84] are caused by complex rearrangements (a combination of duplication, translocation and circularization) involving the C-KIT gene. Mechanisms of these rearrangements are similar to those proposed for B chromosome (as well as HSR and DM) formation. This may indicate that the genomic regions involved in such rearrangements are inherently unstable in different species and perhaps represent recombination hotspots. Based on this example one may speculate that B chromosomes are likely to originate from regions with a high frequency of illegitimate (non-homologous) recombination or evolutionary breakpoints. 
Small supernumerary marker chromosomes (sSMCs) are found in human populations with a frequency of $1 / 2000$. Phenotypic effects of sSMCs vary from normal to serious clinical syndromes. As well as B chromosomes, they can include euchromatic and heterochromatic regions, are mitotically unstable and have predominantly maternal transmission. Interestingly, most sSMCs originate from the the p-arm of chromosome 15 [85]. Although in many respects sSMCs and Bs are similar, the latter acquired a drive mechanism allowing for accumulation through generations in populations. Thus sSMCs can serve as a model of the early evolution of Bs [12].

In summary, research on the genetic content of $B$ chromosomes enables discussion of their origin and evolution, as well as of the molecular mechanisms of irregular behavior in cell division coupled with persistence over many generations. Little is yet known about the interactions between $\mathrm{B}$ chromosomes and the main genome; Bs are a separate yet communicating pool of genetic diversity which can increase the variability of the main genome. Further research carefully examining the borders of amplification regions and comparing them with autosomal homologs will shed light on rearrangement events that took place millions of years ago.

\section{Conclusion and perspectives}

The emerging science of genomics allows large amounts of information about the structure and function of specific genomic regions to be obtained. Detailed characterization of vertebrate $\mathrm{B}$ chromosomes by modern technologies might reveal new important functional elements localized in supernumeraries, help estimate their possible effect on host organisms, and suggest new scenarios and mechanisms of vertebrate genome evolution. Indeed, recently obtained data clearly indicate that the role of B chromosomes in evolution and their influence on the host were underestimated. Future genome projects [86] should consider a possible role of B chromosomes in various cellular and evolutionary processes.

\section{Competing interests}

The authors declare that they have no competing interests.

\section{Authors' contributions}

AIM, PVD, AVK, and VAT carried out the molecular genetic studies. AVK participated in the sequence alignment and analysis. AIM, PVD, ASG, VTV, AVK, and VAT drafted the manuscript. All authors read and approved the final manuscript.

\section{Acknowledgements}

We are grateful to Jennifer L. Johnson for help with figure preparation and critical reading of the manuscript and Jessica P. Hekman for editing the manuscript. This work was supported by the Russian Foundation of Basic Research (RFBR № 12-04-00659-a), by a grant of Russian Academy of Sciences (Molecular and Cellular Biology) and Campus Research Board of the University of Illinois at Urbana Champaign.

\section{Author details}

'Institute of Molecular and Cellular Biology SB RAS, Novosibirsk 630090, Russia. ${ }^{2}$ Theodosius Dobzhansky Center for Genome Bioinformatics, St. Petersburg State University, St. Petersburg, Russia. ${ }^{3}$ Novosibirsk State

University, Novosibirsk, Russia. ${ }^{4}$ Museum National d'Histoire Naturelle, Origine, Structure et Evolution de la Biodiversite, Paris, France. ${ }^{5}$ Department of Animal Sciences, The University of Illinois at Urbana-Champaign, Champaign, USA.

Received: 8 October 2014 Accepted: 5 December 2014

Published online: 17 December 2014

\section{References}

1. Wilson EB: The supernumerary chromosomes of Hemiptera. Science 1907, 26:870-871.

2. Gotoh K: Über die Chromosomenzahl von Secale cereale, L. Bot Mag Tokyo 1924, 38:135-152.

3. Kuwada Y: On the number of chromosomes in maize. Bot Mag Tokyo 1925, 39:227-234.

4. Longley AE: Supernumerary chromosomes in Zea mays. J Agric Res 1927, 35:769-784.

5. Randolph LF: Types of supernumerary chromosomes in maize. Anat Rec 1928, 41:102.

6. Vujošević $M$, Blagojević J: B chromosomes in populations of mammals. Cytogenet Genome Res 2004, 106:247-256.

7. Volobujev VT: B-chromosomes system of the mammals. Caryologia 1981 $34: 1-23$.

8. Camacho JPM, Sharbel TF, Beukeboom LW: B-chromosome evolution. Philos Trans R Soc Lond B Biol Sci 2000, 355:163-178.

9. Houben A, Banaei-Moghaddam AM, Klemme S, Timmis JN: Evolution and biology of supernumerary B chromosomes. Cell Mol Life Sci 2014, 71:467-478.

10. Palestis BG, Burt A, Jones RN, Trivers R: B chromosomes are more frequent in mammals with acrocentric karyotypes: support for the theory of centromeric drive. Proc R Soc Lond B Biol Sci 2004, 271(Suppl 3):S22-S24.

11. Balaban-Malenbaum G, Gilbert F: Double minute chromosomes and the homogeneously staining regions in chromosomes of a human neuroblastoma cell line. Science 1977, 198:739-741.

12. Liehr T, Mrasek K, Kosyakova N, Ogilvie CM, Vermeesch J, Trifonov V, Rubtsov N: Small supernumerary marker chromosomes (sSMC) in humans; are there B chromosomes hidden among them. Mol Cytogenet 2008, 1:12.

13. Patton JL: A complex system of chromosomal variation in the pocket mouse, Perognathus baileyi Merriam. Chromosoma 1972, 36:241-255.

14. Patton JL: B-chromosome systems in the pocket mouse, Perognathus baileyi: meiosis and C-band studies. Chromosoma 1977, 60:1-14.

15. Volobujev VT: B-chromosome system of the Asiatic forest mouse Apodemus peninsulae (Rodentia, Muridae). I. Structure of karyotype, C- and G-bands and B-chromosomes variation pattern. Genetika 1980, 16:1277-1283

16. Potapov VA, Solov'ev W, Romashchenko AG, Sosnovtsev SV, Ivanov SV: Features of the structure and evolution of complex, tandemly organized Bsp-repeats in the fox genome. I. Structure and internal organization of the BamHI-dimer. Mol Biol (Mosk) 1990, 24:1649-1665.

17. Peppers JA, Wiggins LE, Baker RJ: Nature of $B$ chromosomes in the harvest mouse Reithrodontomys megalotis by fluorescence in situ hybridization (FISH). Chromosome Res 1997, 5:475-479.

18. Wurster-Hill DH, Ward OG, Davis BH, Park JP, Moyzis RK, Meyne J: Fragile sites, telomeric DNA sequences, B chromosomes, and DNA content in raccoon dogs, Nyctereutes procyonoides, with comparative notes on foxes, coyote, wolf, and raccoon. Cytogenet Genome Res 1988, 49:278-281

19. Szczerbal I, Switonski M: B chromosomes of the Chinese raccoon dog (Nyctereutes procyonoides procyonoides Gray) contain inactive NOR-like sequences. Caryologia 2003, 56:213-216.

20. Stitou S, de La Guardia RD, Jiménez R, Burgos M: Inactive ribosomal cistrons are spread throughout the B chromosomes of Rattus rattus (Rodentia, Muridae). Implications for their origin and evolution. Chromosome Res 2000, 8:305-311.

21. Rubtsov NB, Karamysheva TV, Andreenkova OV, Bochkaerev MN, Kartavtseva IV, Roslik GV, Borissov YM: Comparative analysis of micro and macro B chromosomes in the Korean field mouse Apodemus peninsulae 
(Rodentia, Murinae) performed by chromosome microdissection and FISH. Cytogenet Genome Res 2004, 106:289-294.

22. Teruel M, Cabrero J, Perfectti F, Camacho JPM: B chromosome ancestry revealed by histone genes in the migratory locust. Chromosoma 2010 119:217-225.

23. Yang F, O'Brien PCM, Wienberg J, Neitzel H, Lin CC, Ferguson-Smith MA: Chromosomal evolution of the Chinese muntjac (Muntiacus reevesi). Chromosoma 1997, 106:37-43.

24. Yang F, O'Brien PCM, Milne BS, Graphodatsky AS, Solanky N, Trifonov V, Rens W, Sargan D, Ferguson-Smith MA: A complete comparative chromosome map for the dog, red fox, and human and its integration with canine genetic maps. Genomics 1999, 62:189-202.

25. Trifonov VA, Perelman PL, Kawada S-I, Iwasa MA, Oda S-I, Graphodatsky AS Complex structure of B-chromosomes in two mammalian species: Apodemus peninsulae (Rodentia) and Nyctereutes procyonoides (Carnivora). Chromosome Res 2002, 10:109-116.

26. Ovcharenko I, Loots GG, Nobrega MA, Hardison RC, Miller W, Stubbs L: Evolution and functional classification of vertebrate gene deserts. Genome Res 2005, 15:137-145.

27. Bejerano G, Pheasant M, Makunin I, Stephen S, Kent WJ, Mattick JS, Haussler D: Ultraconserved elements in the human genome. Science 2004, 304:1321-1325.

28. Ulitsky I, Bartel DP: lincRNAs: genomics, evolution, and mechanisms. Cell 2013, 154:26-46.

29. Graphodatsky AS, Yang F, O'Brien PCM, Serdukova N, Milne BS, Trifonov V, Ferguson-Smith MA: A comparative chromosome map of the Arctic fox, red fox and dog defined by chromosome painting and high resolution G-banding. Chromosome Res 2000, 8:253-263.

30. Beliaev DK, Volobuev VT, Radzhabli SI, Trut LN: Polymorphism and mosaicism for additional chromosomes in silver foxes. Genetika 1974, 10:58-67.

31. Bhatnagar VS: Microchromosomes in the somatic cells of Vulpes bengalensis Shaw. Chromosome Inf Serv 1973, 15:32.

32. Chiarelli AB: The chromosomes of the Canidae. In Wild Canids Their Syst Behav Ecol Evol. New York: Van Nostrand Reinhold Co; 1975:40-53.

33. Yosida TH, Wada MY: Cytogenetical studies on the Japanese raccoon dog. VI. Distribution of B-chromosomes in 1,372 cells from 13 specimens, with special note on the frequency of the Robertsonian fission. Proc Jpn Acad Ser B Phys Biol Sci 1984, 60:301-305.

34. Ward OG, Wurster-Hill DH, Ratty FJ, Song Y: Comparative cytogenetics of Chinese and Japanese raccoon dogs, Nyctereutes procyonoides. Cytogenet Genome Res 1987, 45:177-186.

35. Hsu TC, Benirschke K: Atelocynus microtis. In Atlas of Mammalian Chromosomes, Volume Volume 4. New York: Springer-Verlag; 1973:178,

36. Pieńkowska-Schelling A, Schelling C, Zawada M, Yang F, Bugno M, Ferguson-Smith M: Cytogenetic studies and karyotype nomenclature of three wild canid species: maned wolf (Chrysocyon brachyurus), bat-eared fox (Otocyon megalotis) and fennec fox (Fennecus zerda). Cytogenet Genome Res 2008, 121:25-34

37. Wurster-Hill DH, Ward OG, Kada H, Whittemore S: Banded chromosome studies and B chromosomes in wild-caught raccoon dogs, Nyctereutes procyonoides viverrinus. Cytogenet Genome Res 1986, 42:85-93.

38. Volobujev VT, Radzhabli SI, Belyaeva ES: Investigation of the nature and the role of additional chromosomes in silver foxes. III. Replication pattern in additional chromosomes. Genetika 1976, 12:30.

39. Radzhabli SI, Isaenko AA, Volobujev VT: Investigation of the nature and the role of additional chromosomes in silver fox. IV. B-chromosomes behaviour in meiosis. Genetika 1978, 14:438-443.

40. Graphodatsky AS, Kukekova AV, Yudkin DV, Trifonov VA, Vorobieva NV Beklemisheva VR, Perelman PL, Graphodatskaya DA, Trut LN, Yang F, Ferguson-Smith MA, Acland GM, Aguirre GD: The proto-oncogene C-KIT maps to canid B-chromosomes. Chromosome Res 2005, 13:113-122.

41. Vandenbark GR, DeCastro CM, Taylor H, Dew-Knight S, Kaufman RE: Cloning and structural analysis of the human c-kit gene. Oncogene 1992, 7:1259-1266.

42. Ashman LK: The biology of stem cell factor and its receptor C-kit. Int J Biochem Cell Biol 1999, 31:1037-1051.

43. Besmer P, Murphy JE, George PC, Qiu F, Bergold PJ, Lederman L, Snyder HW, Brodeur D, Zuckerman EE, Hardy WD: A new acute transforming feline retrovirus and relationship of its oncogene $v$-kit with the protein kinase gene family. 1986
44. Heinrich MC, Blanke CD, Druker BJ, Corless CL: Inhibition of KIT tyrosine kinase activity: a novel molecular approach to the treatment of KIT-positive malignancies. J Clin Oncol 2002, 20:1692-1703.

45. Giebel LB, Spritz RA: Mutation of the KIT (mast/stem cell growth factor receptor) protooncogene in human piebaldism. Proc Natl Acad Sci 1991, 88:8696-8699.

46. Geissler EN, Ryan MA, Housman DE: The dominant-white spotting (M) locus of the mouse encodes the c-kit proto-oncogene. Cell 1988, 55:185-192.

47. Tan JC, Nocka K, Ray P, Traktman P, Besmer P: The dominant W42 spotting phenotype results from a missense mutation in the c-kit receptor kinase. Science 1990, 247:209-212.

48. 48. Johnson JL, Kosyza A, Kharlamova AV, Gulevich RG, Perelman PL, Fong HTW, Vladimirova AV, Oskina IN, Trut LN, Kukekova AV: Platinum coat color in red fox (Vulpes vulpes) is caused by a mutation in an autosomal copy of C-KIT. Anim Genet. In press

49. Andersson L: Studying phenotypic evolution in domestic animals: a walk in the footsteps of Charles Darwin. In Cold Spring Harb Symp Quant Biol. New York: Cold Spring Harbor Laboratory Press; 2010. sqb-2009.

50. David VA, Menotti-Raymond M, Wallace AC, Roelke M, Kehler J, Leighty R, Eizirik E, Hannah SS, Nelson G, Schäffer AA, Connelly CJ, O'Brien SJ, Ryugo DK: Endogenous Retrovirus Insertion in the KIT Oncogene Determines White and White spotting in Domestic Cats. G3 Genes Genomes Genet 2014, 4:1881-1891.

51. Yudkin DV, Trifonov VA, Kukekova AV, Vorobieva NV, Rubtsova NV, Yang F, Acland GM, Ferguson-Smith MA, Graphodatsky AS: Mapping of KIT adjacent sequences on canid autosomes and B chromosomes. Cytogenet Genome Res 2007, 116:100-103.

52. Telenius H, Carter NP, Bebb CE, Nordenskjo "Id M, Ponder BAJ, Tunnacliffe A: Degenerate oligonucleotide-primed PCR: General amplification of target DNA by a single degenerate primer. Genomics 1992, 13:718-725.

53. Duke Becker SE, Thomas R, Trifonov VA, Wayne RK, Graphodatsky AS, Breen M: Anchoring the dog to its relatives reveals new evolutionary breakpoints across 11 species of the Canidae and provides new clues for the role of B chromosomes. Chromosome Res 2011, 19:685-708.

54. Nyakatura K, Bininda-Emonds OR: Updating the evolutionary history of Carnivora (Mammalia): a new species-level supertree complete with divergence time estimates. BMC Biol 2012, 10:12.

55. Trifonov VA, Dementyeva PV, Larkin DM, O'Brien PC, Perelman PL, Yang F, Ferguson-Smith MA, Graphodatsky AS: Transcription of a protein-coding gene on B chromosomes of the Siberian roe deer (Capreolus pygargus). BMC Biol 2013, 11:1-11.

56. Poletto AB, Ferreira IA, Cabral-de-Mello DC, Nakajima RT, Mazzuchelli J, Ribeiro HB, Venere PC, Nirchio M, Kocher TD, Martins C: Chromosome differentiation patterns during cichlid fish evolution. BMC Genet 2010, 11:50.

57. Poletto $A B$, Ferreira IA, Martins $C$ : The $B$ chromosomes of the African cichlid fish Haplochromis obliquidens harbour $18 \mathrm{~S}$ rRNA gene copies. BMC Genet 2010, 11:1.

58. Fantinatti BE, Mazzuchelli J, Valente GT, Cabral-de-Mello DC, Martins C: Genomic content and new insights on the origin of the $B$ chromosome of the cichlid fish Astatotilapia latifasciata. Genetica 2011, 139:1273-1282.

59. Yoshida K, Terai Y, Mizoiri S, Aibara M, Nishihara H, Watanabe M, Kuroiwa A Hirai H, Hirai Y, Matsuda Y, Okada N: B chromosomes have a functional effect on female sex determination in Lake Victoria cichlid fishes. PLoS Genet 2011, 7:e1002203.

60. Kuroiwa A, Terai Y, Kobayashi N, Yoshida K, Suzuki M, Nakanishi A, Matsuda Y, Watanabe M, Okada N: Construction of chromosome markers from the Lake Victoria cichlid Paralabidochromis chilotes and their application to comparative mapping. Cytogenet Genome Res 2013, 142:112-120.

61. Valente GT, Conte MA, Fantinatti BE, Cabral-de-Mello DC, Carvalho RF, Vicari MR, Kocher TD, Martins C: Origin and evolution of B chromosomes in the cichlid fish Astatotilapia latifasciata based on integrated genomic analyses. Mol Biol Evol 2014, 31:2061-2072. doi:10.1093/molbev/msu148.

62. Schartl M, Nanda I, Schlupp I, Wilde B, Epplen JT, Schmid M, Parzefall J: Incorporation of subgenomic amounts of DNA as compensation for mutational load in a gynogenetic fish. Nature 1995, 373:68-71.

63. Schartl A, Hornung U, Nanda I, Wacker R, Müller-Hermelink H-K, Schlupp I, Parzefall J, Schmid M, Schartl M: Susceptibility to the development of pigment cell tumors in a clone of the Amazon molly, Poecilia formosa, introduced through a microchromosome. Cancer Res 1997, 57:2993-3000. 
64. Lamatsch DK, Trifonov V, Schories S, Epplen JT, Schmid M, Schartl M: Isolation of a cancer-associated microchromosome in the sperm-dependent parthenogen Poecilia formosa. Cytogenet Genome Res 2011, 135:135-142.

65. Miao VP, Covert SF, VanEtten HD: A fungal gene for antibiotic resistance on a dispensable ("B") chromosome. Science 1991, 254:1773-1776.

66. Miao VP, Matthews DE, VanEtten HD: Identification and chromosomal locations of a family of cytochrome P-450 genes for pisatin detoxification in the fungus Nectrla haematococca. Mol Gen Genet MGG 1991, 226:214-223.

67. Han Y, Liu X, Benny U, Kistler HC, VanEtten HD: Genes determining pathogenicity to pea are clustered on a supernumerary chromosome in the fungal plant pathogen Nectria haematococca. Plant J 2001, 25:305-314.

68. Coleman JJ, Rounsley SD, Rodriguez-Carres M, Kuo A, Wasmann CC, Grimwood J, Schmutz J, Taga M, White GJ, Zhou S, Schwartz DC, Freitag M, Ma L, Danchin EGJ, Henrissat B, Coutinho PM, Nelson DR, Straney D, Napoli CA, Barker BM, Gribskov M, Rep M, Kroken S, Molnár I, Rensing C, Kennell JC, Zamora J, Farman ML, Selker EU, Salamov A, et al: The genome of Nectria haematococca: contribution of supernumerary chromosomes to gene expansion. PLoS Genet 2009, 5:e1000618.

69. Jones $N$, Houben $A$ : $B$ chromosomes in plants: escapees from the $A$ chromosome genome? Trends Plant Sci 2003, 8:417-423.

70. Klemme S, Banaei-Moghaddam AM, Macas J, Wicker T, Novák P, Houben A: High-copy sequences reveal distinct evolution of the rye $B$ chromosome. New Phytol 2013, 199:550-558.

71. Endo TR, Nasuda S, Jones N, Dou Q, Akahori A, Wakimoto M, Tanaka H, Niwa K, Tsujimoto H: Dissection of rye B chromosomes, and nondisjunction properties of the dissected segments in a common wheat background. Genes Genet Syst 2008, 83:23-30.

72. Banaei-Moghaddam AM, Meier K, Karimi-Ashtiyani R, Houben A: Formation and expression of pseudogenes on the $B$ chromosome of rye. Plant Cell Online 2013, 25:2536-2544.

73. Martis MM, Klemme S, Banaei-Moghaddam AM, Blattner FR, Macas J, Schmutzer T, Scholz U, Gundlach H, Wicker T, Šimková H, Novák P, Neumann P, Kubaláková M, Bauer E, Haseneyer G, Fuchs J, Doležel J, Stein N, Mayer KFX, Houben A: Selfish supernumerary chromosome reveals its origin as a mosaic of host genome and organellar sequences. Proc Natl Acad Sci 2012, 109:13343-13346.

74. Dherawattana A, Sadanaga K: Cytogenetics of a crown rust-resistant hexaploid oat with 42+ 2 fragment chromosomes. Crop Sci 1973, 13:591-594.

75. Ruiz-Estevez M, Lopez-Leon MD, Cabrero J, Camacho JPM: B-chromosome ribosomal DNA is functional in the grasshopper Eyprepocnemis plorans. Plos One 2012, 7:e36600.

76. Trifonov VA, Dementyeva PV, Beklemisheva VR, Yudkin DV, Vorobieva NV, Graphodatsky AS: Supernumerary chromosomes, segmental duplications, and evolution. Russ J Genet 2010, 46:1094-1096.

77. Suyama M, Harrington E, Bork P, Torrents D: Identification and analysis of genes and pseudogenes within duplicated regions in the human and mouse genomes. PLoS Comput Biol 2006, 2:e76.

78. Moller MJ, Chaudhary R, Hellmen E, Höyheim B, Chowdhary B, Andersson L: Pigs with the dominant white coat color phenotype carry a duplication of the KIT gene encoding the mast/stem cell growth factor receptor. Mamm Genome 1996, 7:822-830

79. Beghini A, Cairoli R, Morra E, Larizza L: In vivo differentiation of mast cells from acute myeloid leukemia blasts carrying a novel activating ligand-independent C-kit mutation. Blood Cells Mol Dis 1998, 24:262-270.

80. Marklund S, Kijas J, Rodriguez-Martinez H, Rönnstrand L, Funa K, Moller M, Lange D, Edfors-Lilja I, Andersson L: Molecular basis for the dominant white phenotype in the domestic pig. Genome Res 1998, 8:826-833.

81. Kaufman RJ, Brown PC, Schimke RT: Amplified dihydrofolate reductase genes in unstably methotrexate-resistant cells are associated with double minute chromosomes. Proc Natl Acad Sci 1979, 76:5669-5673.

82. Storlazzi CT, Lonoce A, Guastadisegni MC, Trombetta D, D'Addabbo P, Daniele G, L'Abbate A, Macchia G, Surace C, Kok K, Ullmann R, Purgato S, Palumbo O, Carella M, Ambros PF, Rocchi M: Gene amplification as double minutes or homogeneously staining regions in solid tumors: Origin and structure. Genome Res 2010, 20:1198-1206.

83. Durkin K, Coppieters W, Drögemüller C, Ahariz N, Cambisano N, Druet T, Fasquelle C, Haile A, Horin P, Huang L, Kamatani Y, Karim L, Lathrop M, Moser S, Oldenbroek K, Rieder S, Sartelet A, Sölkner J, Stålhammar H, Zelenika D, Zhang Z, Leeb T, Georges M, Charlier C: Serial translocation by means of circular intermediates underlies colour sidedness in cattle. Nature 2012, 482:81-84.

84. Venhoranta H, Pausch H, Wysocki M, Szczerbal I, Hänninen R, Taponen J, Uimari P, Flisikowski K, Lohi H, Fries R, Switonski M, Andersson M: Ectopic KIT copy number variation underlies impaired migration of primordial germ cells associated with gonadal hypoplasia in cattle (Bos taurus). PLOS ONE 2013, 8:e75659.

85. Liehr T, Claussen U, Starke H: Small supernumerary marker chromosomes (sSMC) in humans. Cytogenet Genome Res 2004, 107:55-67.

86. Haussler D, O'Brien SJ, Ryder OA, Barker FK, Clamp M, Crawford AJ, Hanner R, Hanotte O, Johnson WE, McGuire JA, Miller W, Murphy RW, Murphy WJ, Sheldon FH, Sinervo B, Venkatesh B, Wiley EO, Allendorf FW, Amato G, Baker CS, Bauer A, Beja-Pereira A, Bermingham E, Bernardi G, Bonvicino CR, Brenner S, Burke T, Cracraft J, Diekhans M, Edwards S, et al: Genome $10 \mathrm{~K}$ : a proposal to obtain whole-genome sequence for 10000 vertebrate species. J Hered 2009, 100:659-674.

doi:10.1186/s13039-014-0099-y

Cite this article as: Makunin et al: Genes on B chromosomes of vertebrates. Molecular Cytogenetics 2014 7:99.

\section{Submit your next manuscript to BioMed Central and take full advantage of:}

- Convenient online submission

- Thorough peer review

- No space constraints or color figure charges

- Immediate publication on acceptance

- Inclusion in PubMed, CAS, Scopus and Google Scholar

- Research which is freely available for redistribution

Submit your manuscript at www.biomedcentral.com/submit
C) Biomed Central 